\title{
Inverse Correlation of Ability to Produce Aflatoxin and Aspergillus Colonization of Maize Seed
}

\author{
Kenneth C. Ehrlich, Qijian Wei, Robert L. Brown, Deepak Bhatnagar \\ Southern Regional Research Center, New Orleans, USA. \\ Email: ken.ehrlich@ars.usda.gov \\ Received April 23 $3^{\text {rd }}$, 2011; revised May 25 ${ }^{\text {th }}$ 2011; accepted June $3^{\text {rd }}, 2011$.
}

\begin{abstract}
Seeds of aflatoxin-resistant and aflatoxin-susceptible maize lines were inoculated with conidia of aflatoxin-producing Aspergillus flavus or A. parasiticus isolates or isogenic non-producing mutants. Conidia were recovered from resistant maize seed after seven days in significantly lower amounts for aflatoxin-producing A. flavus and A. parasiticus strains than for isogenic mutants incapable of aflatoxin production. This result helps to explain why, in currently used biocontrol strategies for aflatoxin elimination, non-aflatoxigenic isolates are able to out-compete aflatoxin-producing isolates for invasion of the seed.
\end{abstract}

Keywords: Spores, Gene Disruption, Biocontrol, Fungi

\section{Introduction}

Because fungi rarely grow in pure culture in natural environments [1-6], their ability to elaborate secondary metabolites is affected by competition with other microorganisms [7-9]. Contamination of maize, cotton, peanuts and tree nuts by the toxic and carcinogenic secondary metabolites of $A$. flavus, the aflatoxins, is a persistent problem in the United States and other countries [10]. Competition of aflatoxin-producing $A$. flavus with $A$. flavus isolates incapable of aflatoxin production by introducing the latter into the soil of fields where contamination occurs or is likely to occur has been tried as a way to reduce aflatoxin contamination of crops [11-14]. This displacement strategy has been tried on maize and peanuts using different strains of $A$. flavus with varying levels of success $[15,16]$. Only certain isolates of non- aflatoxigenic $A$. flavus were found to be particularly effective in reducing aflatoxin contamination in cotton and maize $[17,18]$. However, in these studies, comparison was not made among isogenic isolates and the studies did not specifically evaluate the role of aflatoxin production on the ability of $A$. flavus to colonize and contaminate the cotton or maize plant.

Seed contamination by A. flavus depends on many factors including the seed's innate susceptibility, environmental factors that contribute to that susceptibility, the fungal community structure in the soil, and the ability of the fungus to reach and penetrate the seed [19]. Natu- ral populations of A. flavus in agricultural areas often include a high percentage of isolates incapable of aflatoxin production [20]. If equal in their abilities to compete, non-aflatoxigenic isolates in the soil should act as naturally occurring antagonists against aflatoxin-producing isolates to ward off aflatoxin contamination of susceptible plants. To better evaluate the relative abilities of aflatoxin-producing and non-aflatoxin-producing isolates to colonize and contaminate maize seed, we determined the recovery of conidia after inoculation of two varieties of maize with isogenic strains of aflatoxin-producing and non-producing isolates of $A$. flavus and A. parasiticus.

\section{Materials and Methods}

\subsection{Preparation of Disruption Mutants}

Two nia $D^{-}$mutants, an $A$. parasiticus isolate BN009E (BN9) [21] and an A. flavus isolate AF70 (ATCC MYA384), were used as recipients in fungal transformation experiments. Partial replacement of the AF cluster genes, $p k s A$, avfA, with niaD was done as previously described [22]. The isogenic controls were BN9 and AF70 transformed with the niaD ${ }^{-}$selection marker, pSL82 [23].

\subsection{Preparation of Conidia}

Fungal isolates were grown on 5\% V8 juice, 2\% agar plates in the dark at $30^{\circ} \mathrm{C}$. After seven days, the conidia were harvested in $0.1 \%$ Triton $\times 100$ and vortexed for one min with glass beads ( $3 \mathrm{~mm}$ mean diameter) to ob- 
tain an even suspension. The conidial concentration was adjusted to $1 \times 10^{7} \mathrm{ml}^{-1}$ in $0.1 \%$ Triton $\times 100$. Spore density was estimated both by hemocytometer counting and plating for colony-forming units $(\mathrm{CFU} / \mathrm{ml})$. The resulting conidial suspension was used as the inoculum for both susceptible and resistant varieties of maize (see below).

\subsection{Maize Kernel Screening Assay}

Kernels of an aflatoxin-susceptible variety of maize (Pioneer hybrid 3142, Brown, unpublished data) were obtained from Pioneer Hi-Bred International, Inc. (Johnston, IA). Kernels of another variety of aflatoxin-susceptible maize (SC212M) were obtained from the, Maize Host Plant Resistance Research Unit, USDA-ARS, Mississippi State University, University, MS. Kernels of an aflatoxin-resistant variety of inbred maize (MI82) [24] were obtained from the Department of Plant Pathology, University of Illinois, Urbana, IL.

The kernel screening assay (KSA) previously used to determine the ability of $A$. flavus to invade maize kernels [25], was used to compare the infectivity of the control and mutant isolates of $A$. flavus and $A$. parasiticus. For this assay, seeds were placed individually in plastic caps that were then placed in open petri dishes $(60 \times 15 \mathrm{~mm})$. Individual culture dishes containing four seeds were placed side by side in a clear tray $(243 \times 243 \times 18 \mathrm{~mm})$ lined with 3 -mm chromatography paper. The lid was placed on top of the tray but was not sealed. Seeds were inoculated with $10^{7}$ spores and were incubated at $31^{\circ} \mathrm{C}$ and $100 \%$ relative humidity (RH) for seven days. Each treatment had eight replicates with four seeds in each. After incubation spores were recovered from the seeds by washing in $0.1 \%$ aqueous Triton $\times 100$. Recovered cell amounts were determined by hemocytometer and plating for colony forming units.

\subsection{Statistical Analysis}

Standard ANOVA with single factor and T-tests were conducted using Microsoft Excel to compare responses between the wild-type and isogenic mutants. Differences in responses were considered significant if $P<0.05$.

\section{Results and Discussion}

A kernel screening assay was used previously to screen maize varieties for resistance to aflatoxin accumulation by $A$. flavus [26,27]. For aflatoxin to accumulate in the seed, the conidia must contact the seed, germinate, penetrate the seed, and reproduce within the seed. The resulting conidial population density recovered from a seed, therefore, provides a measure of the fungus's ability to invade and colonize the seed. Figure 1 shows the comparison of conidial yields of isogenic wild-type and avfA and pksA mutants of $A$. parasiticus and A. flavus recov-

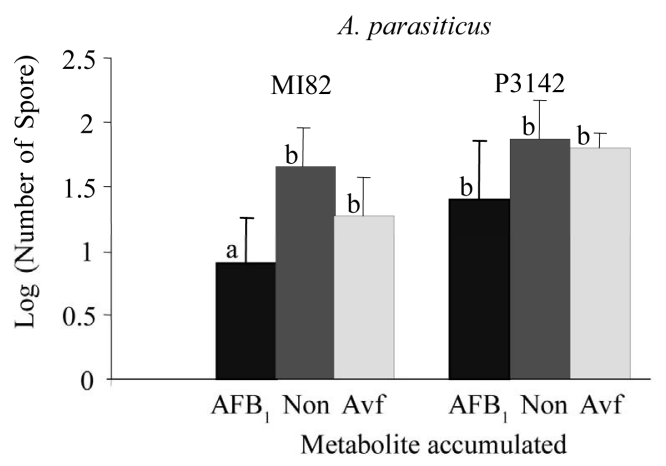

(a)

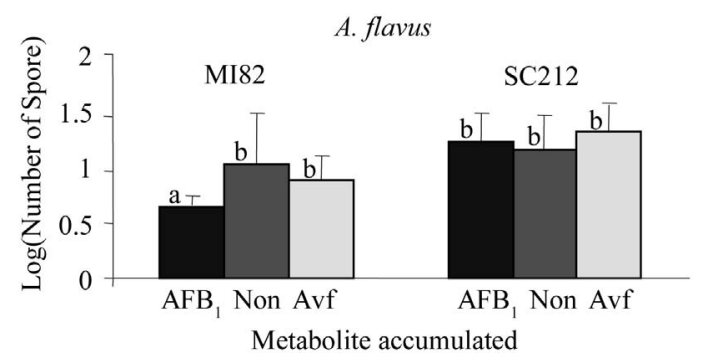

(b)

Figure 1. Spore recovery after treatment of resistant (M182) and susceptible (P3142 and SC212) varieties of maize with isogenic A. A. parasiticus and B. A. flavus isolates that accumulate $\mathrm{AFB}_{1}$ (BN9pSL82 and AF70pSL82), Avf (averufin; BN94avfA and AF704avfA) and no metabolites (None; BN9 $\Delta p k s A$ and AF70 $\Delta p k s A)$. Values with the same letter are not significantly different $(P>0.01)$.

ered after incubation with the two varieties of maize. For both $A$. parasiticus and $A$. flavus, significantly $(P<0.01)$ lower spore recovery was found for the aflatoxin-producing parental strain compared to the isogenic non- aflatoxin-producing mutant on the resistant maize variety (MI82). No significant difference in spore recovery was found for either of the susceptible varieties of maize (P3142 or SC212) inoculated with the same isolates. Therefore, production of aflatoxin is not only not necessary for contamination of the maize seed but can provide a slight, but, at least for the resistant maize variety, significant burden on the isolate regarding its ability to contaminate the seed.

A previous study using isogenic mutants of $A$. nidulans as the test organism found that spore recovery from maize was proportional to production of sterigmatocystin (a precursor of aflatoxin) and other precursor metabolites [28]. This observation suggested that in A. nidulans spore production is closely tied to the fungus's ability to produce sterigmatocystin.

Both fungal development, as measured by spore formation, and secondary metabolism, as measured by sterigmatocystin production, are later stages in fungal growth and require some of the same regulatory machin- 
ery [29-31]. Production of secondary metabolites is an energy intensive process [32-34]. This expenditure of energy for aflatoxin production could come at the expense of the energy needed for conidial development and invasion of the plant. The increased ability of the nonaflatoxin producing strains to invade and colonize the resistant maize seeds could be due to an increased availability of energy that would normally be expended on aflatoxin production. The lack of a significant difference in the ability of the fungus to invade the aflatoxin-susceptible maize varieties suggests that less metabolic energy may be required for the Aspergillus isolates to mount an invasion of these varieties of seed.

Alternatively, the resistant variety, but not the susceptible variety, of maize may produce fungal inhibitory factors that ward off invasion by the fungus depending on its ability or inability to make aflatoxins. Since aflatoxins are transported from the fungal cell, the plant response to the presence of the fungus may be only experienced if it is able to respond to this secondary metabolite. The opposite results observed in $A$. nidulans could be a result of inherent differences in the two species with regard their use of metabolic energy in sterigmatocystin production and conidial development or to the fact that sterigmatocystin is predominantly intracellular and does not initiate a plant defensive response. In either case, our results suggest that $A$. flavus non-aflatoxin-producing strains have an equal ability or slight advantage over aflatoxin-producing strains in their ability to invade the seed and displace an aflatoxin-producing strain. Therefore, the strategy of introducing non-aflatoxin-producing $A$. flavus to limit aflatoxin contamination of maize and cotton by A. flavus is supported by our results.

\section{REFERENCES}

[1] K. Ehrlich, "Effect on Aflatoxin Production of Competition between Wild-Type and Mutant Strains of Aspergillus Parasiticus,” Mycopathologia, Vol. 97, No. 2, 1987, pp. 93-96. doi:10.1007/BF00436844

[2] P. J. Cotty and P. Bayman, "Competitive Exclusion of a Toxigenic Strain of Aspergillus Flavus by an Atoxigenic Strain,” Phytopathology, Vol. 83, No. 12, 1993, pp. 12831287. doi:10.1094/Phyto-83-1283

[3] D. T. Wicklow, J. R. Bobell and D. E. Palmquist, "Effect of Intraspecific Competition by Aspergillus Flavus on Aflatoxin Formation in Suspended Disc Culture," Mycological Research, Vol. 107, No. 5, 2003, pp. 617-623.

[4] J. J. Pan and G. May, "Fungal-Fungal Associations Affect the Assembly of Endophyte Communities in Maize (Zea Mays)," Microbial Ecology, Vol. 58, No. 3, 2009, pp. 668-678. doi:10.1007/s00248-009-9543-7

[5] C. Mille-Lindblom, H. Fischer and L. J. Tranvik, "Antagonism between Bacteria and Fungi: Substrate Competition and a Possible Tradeoff between Fungal Growth and Tolerance towards Bacteria,” Oikos, Vol. 113, No. 2, 2006, pp. 233-242.

doi:10.1111/j.2006.0030-1299.14337.x

[6] L. Losada, O. Ajayi, J. C. Frisvad, J. Yu and W. C. Nierman, "Effect of Competition on the Production and Activity of Secondary Metabolites in Aspergillus Species," Medical Mycology, Vol. 47, Suppl. 1, 2009, pp. S88-96. doi:10.1080/13693780802409542

[7] K. Ehrlich, A. Ciegler, M. A. Klich and L. Lee, "Fungal Competition and Mycotoxin Production on Corn," Experientia, Vol. 41, 1985, pp. 691-693. doi:10.1007/BF02007725

[8] A. Velluti, S. Marin, L. Bettucci, A. J. Ramos and V. Sanchis, "The Effect of Fungal Competition on Colonization of Maize Grain by Fusarium Moniliforme, F. Proliferatum and F. Graminearum and on Fumonisin B-1 and Zearalenone Formation,” International Journal of Food Microbiology, Vol. 59, No. 1-2, 2000, pp. 59-66. doi:10.1016/S0168-1605(00)00289-0

[9] N. Ramakrishna, J. Lacey and J. E. Smith, “The Effects of Fungal Competition on Colonization of Barley Grain by Fusarium Sporotrichioides on T-2 Toxin Formation," Food Additives and Contaminants, Vol. 13, No. 8, 1996, pp. 939-948.

[10] D. Bhatnagar, R. Brown, K. Ehrlich and T. E. Cleveland, "Mycotoxins Contaminating Cereal Grain Crops: Their Occurrence and Toxicity," In: G. G. Khachatourians and D. K. Arora, Eds., Applied Mycology and Biotechnology, Vol. 2, Elsevier B.V., New York, 2002, pp. 171-196.

[11] C. Probst, F. Schulthess and P. J. Cotty, "Impact of Aspergillus Section Flavi Community Structure on the Development of Lethal Levels of Aflatoxins in Kenyan Maize (Zea Mays)," Journal of Applied Microbiology, Vol. 108, No. 2, 2010, pp. 600-610. doi:10.1111/j.1365-2672.2009.04458.x

[12] J. Atehrikeng, P. S. Ojiambo, M. Donner, T. Ikotun, R. A. Sikora, P. J. Cotty and R. Bandyopadhyay, "Distribution and Toxigenicity of Aspergillus Species Isolated from Maize Kernels from Three Agro-Ecological Zones in Nigeria,” International Journal of Food Microbiology, Vol. 122, No. 1-2, 2008, pp. 74-84. doi:10.1016/j.ijfoodmicro.2007.11.062

[13] P. J. Cotty, "Biocompetitive Exclusion of Toxigenic Fungi,” In: D. Barug, Ed., The Mycotoxin Factbook, 2006, pp. 179-197.

[14] K. R. N. Reddy, H. K. Abbas, C. A. Abel, W. T. Shier, C. A. F. Oliveira and C. R. Raghavender, "Mycotoxin Contamination of Commercially Important Agricultural Commodities," Toxin Reviews, Vol. 28, No. 2-3, 2009, pp. 154-168. doi:10.1080/15569540903092050

[15] H. K. Abbas, J. R. Wilkinson, R. M. Zablotowicz, C. Accinelli, C. A. Abel, H. A. Bruns and M. A. Weaver, "Ecology of Aspergillus Flavus, Regulation of Aflatoxin Production, and Management Strategies to Reduce Aflatoxin Contamination of Corn," Toxin Reviews, Vol. 28, No. 2-3, 2009, pp. 142-153. doi:10.1080/15569540903081590

[16] J. W. Dorner and B. W. Horn, "Separate and Combined 
Applications of Nontoxigenic Aspergillus Flavus and $A$. Parasiticus for Biocontrol of Aflatoxin in Peanuts," Mycopathologia, Vol. 163, No. 4, 2007, pp. 215-223. doi:10.1007/s11046-007-9004-0

[17] J. W. Dorner, "Efficacy of a Biopesticide for Control of Aflatoxins in Corn,” Journal of Food Protection, Vol. 73, No. 3, 2010, pp. 495-499.

[18] R. Jaime-Garcia and P. J. Cotty, "Formulations of Aspergillus Flavus AF36 to Improve in-Field Residence and Sporulation," Phytopathology, Vol. 98, No. 6, 2008, pp. S73-S73.

[19] B. W. Horn, "Ecology and Population Biology of Aflatoxigenic Fungi in Soil," Journal of Toxicology-Toxin Reviews, Vol. 22, No. 2-3, 2003, pp. 351-379.

[20] B. W. Horn and J. W. Dorner, "Effect of Nontoxigenic Aspergillus Flavus and A. Parasiticus on Aflatoxin Contamination of Wounded Peanut Seeds Inoculated with Agricultural Soil Containing Natural Fungal Populations," Biocontrol Science and Technology, Vol. 19, No. 3, 2009, pp. 249-262. doi:10.1080/09583150802696541

[21] K. C. Ehrlich, P.-K. Chang, J. Yu and P. J. Cotty, “Aflatoxin Biosynthesis Cluster Gene cypA Is Required for $\mathrm{G}$ Aflatoxin Formation," Applied and Environmental Microbiology, Vol. 70, No. 11, 2004, pp. 6518-6524. doi:10.1128/AEM.70.11.6518-6524.2004

[22] K. C. Ehrlich, Q. Wei and D. Bhatnagar, "Increased Sensitivity of Aspergillus Flavus and A. Parasiticus Polyketide Synthase Mutants to UVB Light," World Mycotoxin Journal, Vol. 3, No. 2010, pp. 263-270.

[23] P. K. Chang, K. C. Ehrlich, J. E. Linz, D. Bhatnagar, T. E. Cleveland and J. W. Bennett, "Characterization of the Aspergillus Parasiticus niaD and niiA Gene Cluster," Current Genetics, Vol. 30, No. 1, 1996, pp. 68-75. doi:10.1007/s002940050102

[24] K. W. Campbell and D. G. White, "Evaluation of Corn Genotypes for Resistance to Aspergillus Ear Rot, Kernal Infection, and Aflatoxin Production," Plant Disease, Vol. 79, No. 1995, pp. 1039-1045.

[25] R. L. Brown, T. E. Cleveland, G. A. Payne, C. P. Woloshuk, K. W. Campbell and D. G. White, "Determination of Resistance to Aflatoxin Production in Maize Kernels and Detection of Fungal Colonization using an Aspergillus Flavus Transformant Expressing Escherichia Coli $\beta$-Glucuronidase,” Phytopathology, Vol. 85, No. 9, 1995, pp. 983-990. doi:10.1094/Phyto-85-983

[26] R. L. Brown, C. S. Brown-Jenco, D. Bhatnagar and G. A. Payne, "Construction and Preliminary Evaluation of an
Aspergillus Flavus Reporter Gene Construct as a Potential Tool for Screening Aflatoxin Resistance,” Journal of Food Protection, Vol. 66, No. 10, 2003, pp. 1927-1931.

[27] Z. Y. Chen, R. L. Brown, T. E. Cleveland, K. F. Damann and J. S. Russin, "Comparison of Constitutive and Inducible Maize Kernel Proteins of Genotypes Resistant or Susceptible to Aflatoxin Production," Journal of Food Protection, Vol. 64, No. 11, 2001, pp. 1785-1792.

[28] H. Wilkinson, A. Ramaswamy, S. C. Sim and N. P. Keller, "Increased Conidiation Associated with Progression along the Sterigmatocystin Biosynthetic Pathway," Mycologia, Vol. 96, 2004, pp. 1190-1198. doi:10.2307/3762134

[29] O. Bayram, S. Krappmann, M. Ni, J. W. Bok, K. Helmstaedt, O. Valerius, S. Braus-Stromeyer, N. J. Kwon, N. P. Keller, J. H. Yu and G. H. Braus, "VelB/VeA/LaeA Complex Coordinates Light Signal with Fungal Development and Secondary Metabolism,” Science, Vol. 320, No. 5882, 2008, pp. 1504-1506. doi:10.1126/science. 1155888

[30] A. M. Calvo, R. A. Wilson, J. W. Bok and N. P. Keller, "Relationship between Secondary Metabolism and Fungal Development," Microbiology and Molecular Biology Reviews, Vol. 66, No. 3, 2002, pp. 447-459. doi:10.1128/MMBR.66.3.447-459.2002

[31] J. K. Hicks, J. H. Yu, N. P. Keller and T. H. Adams, “ $A s-$ pergillus Sporulation and Mycotoxin Production both Require Inactivation of the FadA G Alpha Protein-Dependent Signaling Pathway,” The EMBO Journal, Vol. 16, No. 16, 1997, pp. 4916-4923. doi:10.1093/emboj/16.16.4916

[32] S. N. Khan and T. A. Venkitasubramanian, "Cyclic AMP Pool and Aflatoxin Production in Aspergillus Parasiticus NRRL 3240 and Aspergillus Flavus NRRL 3537," Indian Journal of Biochemistry and Biophysics, Vol. 24, No. 6, 1987, pp. 308-313.

[33] T. A. Venkitasubramanian, R. K. Bhatnagar, S. Saraswathy, V. B. Rao and J. Sivaswami, "Intermediary Metabolism of Aspergillus Parasiticus in Relation to Aflatoxin Biosynthesis in Fungi," Federation of European Microbiological Societies Symposium, No. 13, 1982, pp. 153-165.

[34] R. L. Buchanan, S. B. Jones, W. V. Gerasimowicz, L. L. Zaika, H. G. Stahl and L. A. Ocker, "Regulation of Aflatoxin Biosynthesis: Assessment of the Role of Cellular Energy Status as a Regulator of the Induction of Aflatoxin Production," Applied and Environmental Microbiology, Vol. 53, No. 6, 1987, pp. 1224-1231. 